\title{
A248, a novel synthetic HDAC inhibitor, induces apoptosis through the inhibition of specificity protein 1 and its downstream proteins in human prostate cancer cells
}

\author{
EUN-SUN CHOI ${ }^{1}$, GYOONHEE HAN ${ }^{2}$, SONG-KYU PARK ${ }^{3}$, KIHO LEE $^{3}$, \\ HYUN-JUNG KIM ${ }^{4}$, SUNG-DAE $\mathrm{CHO}^{1}$ and HWAN MOOK KIM ${ }^{5}$
}

\begin{abstract}
${ }^{1}$ Department of Oral Pathology, School of Dentistry and Institute of Oral Bioscience, Brain Korea 21 Project, Chonbuk National University, Jeonju 561-756; ${ }^{2}$ Translational Research Center for Protein Function Control (TRCP), Department of Biotechnology and Department of Biomedical Sciences (WCU Program), Yonsei University, Seoul 120-749;

${ }^{3}$ College of Pharmacy, Korea University, Sejong 339-700; ${ }^{4}$ BioRunx Co., Ltd., Huengduk-gu, Cheongju 361-763;

${ }^{5}$ Gachon Institute of Pharmaceutical Sciences, Gachon University, Yeonsu-gu, Incheon 406-840, Republic of Korea
\end{abstract}

Received December 7, 2012; Accepted April 17, 2013

DOI: $10.3892 / \mathrm{mmr} .2013 .1481$

\begin{abstract}
Histone deacetylase (HDAC) inhibitors are emerging as potent anticancer agents due to their ability to induce apoptosis in various cancer cells, including prostate cancer cells. In the present study, we synthesized a novel HDAC inhibitor, A248, and investigated its apoptotic activity and molecular target in the DU145 and PC3 human prostate cancer cell lines. A248 inhibited the growth of DU145 and PC3 cells and induced apoptosis, as demonstrated by nuclear fragmentation and the accumulation of cells at subG1 phase of cell cycle. The treatment of DU145 and PC3 prostate cancer cells with A248 resulted in the downregulation of specificity protein 1 (Sp1) expression. Since the expression levels of survivin and Mcl-1 depend on Sp1, we also investigated the effects of A248 on survivin and Mcl-1 expression using western blot analysis and immunocytochemistry. The results showed that A248 markedly decreased the expression of survivin and Mcl-1. These data suggest that A248 has apoptotic activity in human prostate cancer cells and that Sp1 may be the molecular target of A248 treatment for inducing apoptosis in prostate cancer cells.
\end{abstract}

Correspondence to: Professor Sung-Dae Cho, Department of Oral Pathology, School of Dentistry and Institute of Oral Bioscience, Chonbuk National University, 664-14, Duckjindong 1ga, Jeonju 561-756, Republic of Korea

E-mail: efiwdsc@chonbuk.ac.kr

Professor Hwan Mook Kim, Gachon Institute of Pharmaceutical Sciences, Gachon University, 7-45 Songdo-dong, Yeonsu-gu, Incheon 406-840, Republic of Korea

E-mail: hwanmook@gachon.ac.kr

Key words: A248, histone deacetylase inhibitor, prostate cancer, specificity protein 1 , survivin, Mcl-1

\section{Introduction}

Prostate cancer is the most common type of cancer and the third leading cause of cancer-related mortalities in males worldwide, according to the World Cancer Report 2003 (1). Conventional management of prostate cancer includes surgery, radiotherapy and androgen deprivation (2). Adjuvant hormone therapy following radiotherapy or surgery is a treatment option frequently offered to males with localized or locally advanced prostate cancer. In males with metastatic androgen-dependent prostate cancer, androgen blockade is the most frequently used treatment. The above-mentioned treatments may be effective and have the potential to provide a high life expectancy by inducing tumor suppression (3). However, patients who initially respond to these therapies often develop a refractory aggressive androgen-independent cancer (4). Therefore, new treatments for prostate cancer patients are required, particularly for patients with androgen-independent cancer.

Based on clinical and pre-clinical studies, the concept of molecular targeting is becoming increasingly promising as a tool to treat prostate cancer. Specificity protein 1 (Sp1) is a sequence-specific transcription factor that binds to the GC box and activates a host of viral and cellular genes. The overexpression or higher binding activity of Spl has been found in various types of human cancer, including pancreatic, breast, gastric, thyroid and prostate cancer (5). Several studies have also reported that the overexpression of Sp1 increases its ability to upregulate vascular endothelial growth factor (VEGF) and survivin $(5,6)$. Our previous studies have demonstrated that $\mathrm{Sp} 1$ protein is significantly overexpressed in prostate cancer cells, and that the inhibition of $\mathrm{Sp} 1$ protein potently induces apoptosis through the downregulation of survivin and $\mathrm{Mcl}-1$ proteins $(7,8)$.

HDAC inhibitors are a class of agents that function via blocking histone deacetylation, thereby modifying chromatin structure and gene transcription (9). According to various studies, HDAC inhibitors are potent anticancer agents that induce cell growth arrest, differentiation and apoptosis in 
human bladder, breast, prostate, lung, ovary and colon cancer and acute myelogenous leukemia (10). Several clinical trials, particularly for cancer therapies, are currently being carried out to examine the therapeutic benefits of HDAC inhibitors. It has recently been demonstrated that HDAC inhibitors markedly reduce prostate cancer growth and metastatic dissemination (11). The HDAC inhibitor Vorinostat (suberoylanilde hydroxamic acid, SAHA) has been approved for the treatment of breast cancer. Additionally, HDAC inhibitors, including TSA, FK228 and LBH589, are also used as anticancer agents (12).

Therefore, the aim of the present study was to investigate the cytotoxic activity and molecular target of A248, a newly synthesized HDAC inhibitor, in androgen-independent human prostate cancer cell lines.

\section{Materials and methods}

Reagents. Sp1 and $\beta$-actin antibodies were purchased from Santa Cruz Biotechnology, Inc. (Santa Cruz, CA, USA). Mcl-1 and survivin antibodies were obtained from Cell Signaling Technology, Inc. (Danvers, MA, USA). 4'-6-Diamidino-2-phenylindole (DAPI) and propidium iodide (PI) were acquired from Sigma-Aldrich (St. Louis, MO, USA). Mcl-1 and survivin antibodies used for immunocytochemistry were purchased from Abcam (Cambridge, MA, USA). IgG antibody was purchased from BD Pharmingen (Franklin Lakes, NJ, USA). A248 was synthesized by the Gachon Institute of Pharmaceutical Sciences, Gachon University (Incheon, Republic of Korea).

Cell culture and chemical treatment. DU145 and PC3 cells were kindly provided by Professor Hwan Mook Kim and were maintained in RPMI-1640 medium containing $10 \%$ fetal bovine serum (FBS) and $100 \mathrm{U} / \mathrm{ml}$ penicillin and streptomycin in a $5 \% \mathrm{CO}_{2}$ atmosphere. Equal numbers of cells were seeded and allowed to attach to the cell culture dishes or plates. When 50-60\% confluence was reached, DU145 and PC3 cells were treated with DMSO or various concentrations of A248 (1, 2 and $4 \mu \mathrm{M}$ ) for $72 \mathrm{~h}$. A248 was dissolved in 0.1\% DMSO (vehicle control).

MTS assay. The effect of A248 on cell viability was evaluated using the CellTiter $96{ }^{\circledR}$ AQueous One Solution Cell Proliferation Assay kit (Promega, Madison, WI, USA). DU145 and PC3 cells were seeded in 96-well plates and incubated with various concentrations of A248 for 24, 48, and 72 h. Following treatment, 3-(4,5-dimethylthiazol-2-yl)-5(3carboxymethonyphenol)-2-(4-sulfophenyl)-2H-tetra zolium (MTS) solution was added to each well $(30 \mu \mathrm{l})$ and incubated at $37^{\circ} \mathrm{C}$. The absorbance was measured at $490 \mathrm{~nm}$ using an ELISA reader (Bio-Tek Instruments, Inc., Madison, WI, USA). The data were expressed as the percentage cell viability compared with that of control cells.

FACS analysis for sub-G1 DNA determination. The effect of A248 on the cell cycle was investigated by FACS analysis. For PI staining, the cells were seeded in $60-\mathrm{mm}^{2}$ dishes. After attachment, DU145 and PC3 cells were treated with various concentrations of A248 for 72 h. Following treatment, floating and attached cells were harvested, washed with phosphate-buffered saline (PBS) and fixed in ice-cold 70\% ethanol. The cells were then washed with PBS and suspended in PI $(0.02 \mathrm{mg} / \mathrm{ml}$ in PBS). All the measurements were performed in triplicate and results were expressed as a fold induction with respect to DMSO-treated cells.

DAPI staining. Apoptosis was determined morphologically using the fluorescent nuclear dye, DAPI. Following treatment with A248 for 72 h, DU145 and PC3 cells were harvested by trypsinization and fixed in $100 \%$ ethanol overnight at $-20^{\circ} \mathrm{C}$. The following day, the cells were stained with DAPI $(2 \mathrm{mg} / \mathrm{ml}$ in PBS), deposited onto slides and observed using a fluorescence microscope to detect apoptotic characteristics.

Western blot analysis. DU145 and PC3 cells were seeded in $60-\mathrm{mm}^{2}$ dishes and treated with DMSO or A248. Whole-cell lysates were extracted with lysis buffer and protein concentrations were measured using a DC Protein Assay (Bio-Rad Laboratories, Inc., Hercules, CA, USA). Samples containing equal amounts of protein were separated by SDS-PAGE and then transferred to Immun-Blot ${ }^{\mathrm{TM}}$ PVDF membranes (Bio-Rad Laboratories, Inc.). The membranes were blocked with 5\% skim milk in TBST at room temperature (RT) for $1 \mathrm{~h}$ and were then incubated with the primary antibodies overnight at $4^{\circ} \mathrm{C}$, followed by incubation with the horseradish peroxidase (HRP)-conjugated secondary antibodies for $90 \mathrm{~min}$ at RT. Antibody-bound proteins were detected using ECL Western Blotting Luminol reagent (Santa Cruz Biotechnology, Inc.) and then exposed to film.

Immunocytochemical analysis. Cells were seeded on 6-well tissue culture plates. The cells were incubated for $72 \mathrm{~h}$ with A248 and fixed and permeabilized with a fixation and permeabilization solution (BD Biosciences, Franklin Lakes, NJ, USA) for $30 \mathrm{~min}$. The cells were then blocked with $1 \%$ bovine serum albumin (BSA) and incubated with the indicated antibodies at $4^{\circ} \mathrm{C}$. Subsequently, the cells were exposed to the FITC-conjugated secondary antibodies for $2 \mathrm{~h}$ at RT and were covered with aluminum foil and were visualized using a fluorescence microscope equipped with the appropriate filters for DAPI and FITC dyes.

Statistical analysis. Statistical analyses of the experimental data were performed using a two-sided Student's t-test. $\mathrm{P}<0.05$ was considered to indicate a statistically significant difference.

\section{Results}

A248 inhibits cell viability of DU145 and PC3 human prostate cancer cells. To investigate the effect of A248 on the cell viability of DU145 and PC3 prostate cancer cells, an MTS assay was initially performed. The cell viability of both cell lines was shown to be significantly decreased by A248 in a concentration- and time-dependent manner (Fig. 1).

A248 induces apoptosis in DU145 and PC3 cells. We then examined whether A248 inhibits cell viability through inducing apoptosis. Cells treated with A248 for $72 \mathrm{~h}$ were 

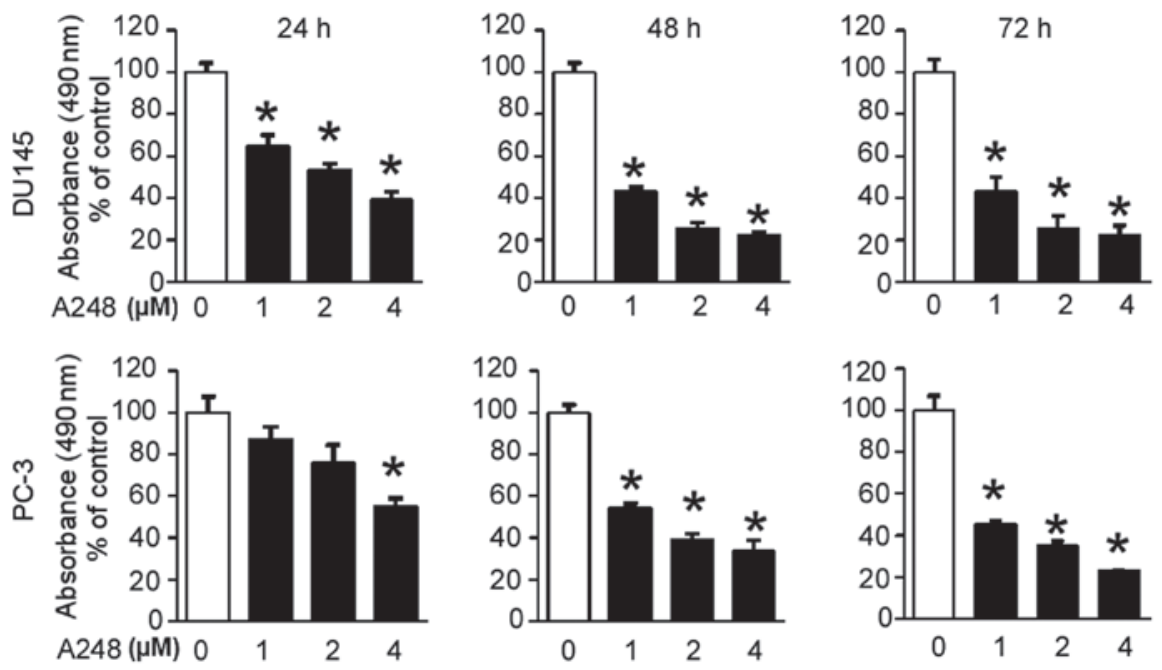

Figure 1. A248 inhibits the cell growth of DU145 and PC3 cells. The cells were seeded and treated with DMSO (vehicle control) or various concentrations of A248 for 24, 48 and $72 \mathrm{~h}$. Following treatment, the cells were analyzed using an MTS assay, as described in Materials and methods. The experiments were performed in triplicate and results are expressed as the mean $\pm \mathrm{SD}$. ${ }^{*} \mathrm{P}<0.05$ compared with the DMSO-treated group. MTS, 3-(4,5-dimethylthiazol-2-yl)5(3-carboxymethonyphenol)-2-(4-sulfophenyl)-2H-tetra zolium.

A
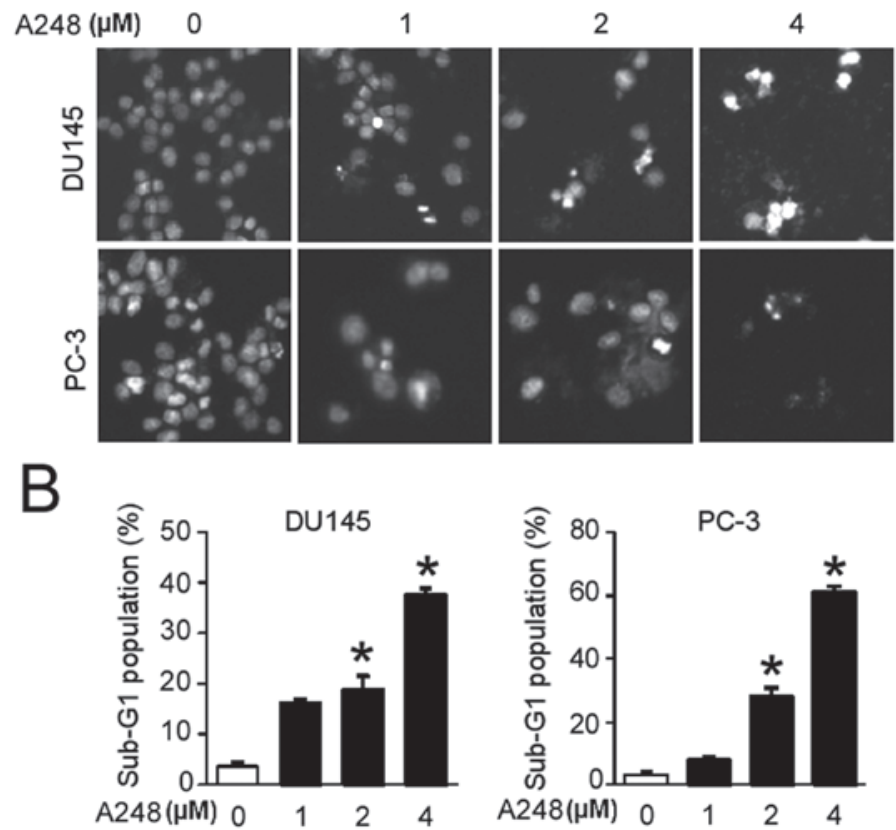

Figure 2. A248 induces apoptosis in DU145 and PC3 cells. The cells were treated with DMSO (vehicle control) or various concentrations of A248 for $72 \mathrm{~h}$. The cells were then harvested and prepared for DAPI staining and flow cytometric analysis, as described in Materials and methods. (A) DNA fragmentation and nuclear condensation were observed by fluorescence microscopy. (B) The sub-G1 cell population was determined by PI staining and flow cytometric analysis, and the accumulation of cells in the sub-G1 phase of the cell cycle (as a percentage of the controls) was quantified. The experiments were performed in triplicate and results are expressed as the mean \pm SD. "P<0.05 compared with the DMSO (vehicle control)-treated cells. DAPI, 4'-6-diamidino-2-phenylindole; PI, propidium iodide.

stained by DAPI solution, and staining was observed using a fluorescence microscope. The results showed that A248 significantly induced nuclei condensation and fragmentation in DU145 and PC3 cells compared with the DMSO (vehicle control)-treated cells (Fig. 2A). We also determined the cell population in the sub-G1 phase of the cell cycle using PI staining in both cell lines. A248 caused an accumulation of cells in the sub-G1 phase of the cell cycle in DU145 and PC3 cells (Fig. 2B). These results suggest that apoptotic cell death may contribute to the growth-inhibitory effect of A248 in DU145 and PC 3 cells.

A248 inhibits Spl protein expression in DU145 and PC3 cells. To determine the mechanism underlying A248-induced apoptosis, we examined whether A248 affects the expression of Sp1 protein in DU145 and PC3 cells. A248 was shown 
A

C

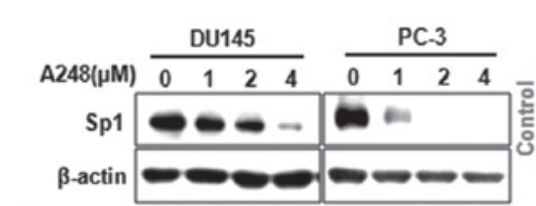

$\lg G$

DG DAPI

Merge

B
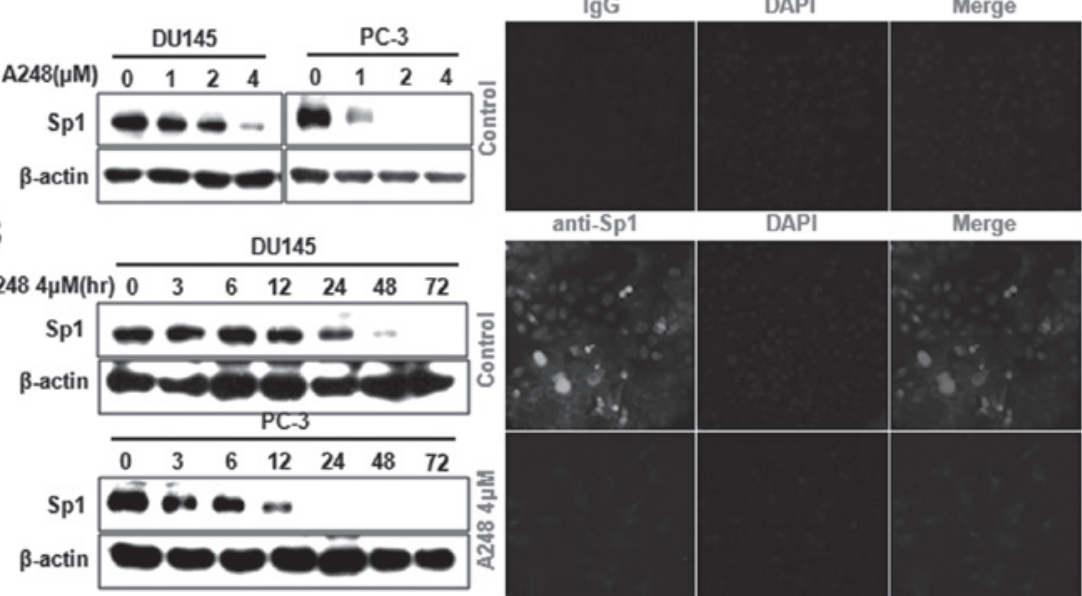

anti-Sp1 DAPI Merge

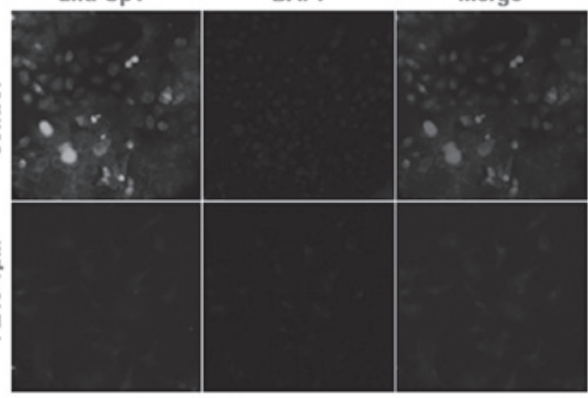

Figure 3. A248 inhibits Sp1 expression in DU145 and PC3 cells. (A) Cells were treated with the indicated concentrations of A248 for 72 h, and alterations in Sp1 protein expression were detected by western blot analysis. (B) The cells were treated with $4 \mu \mathrm{M}$ A248 for the indicated periods of time, and the cell lysates were then detected by Sp1 staining. $\beta$-actin expression was used as an internal loading control. (C) DU145 cells were treated with $4 \mu \mathrm{M}$ A248 for $72 \mathrm{~h}$ and immunostained with IgG or Sp1 antibodies. DAPI, 4'-6-diamidino-2-phenylindole; Sp1, specificity protein 1.

A
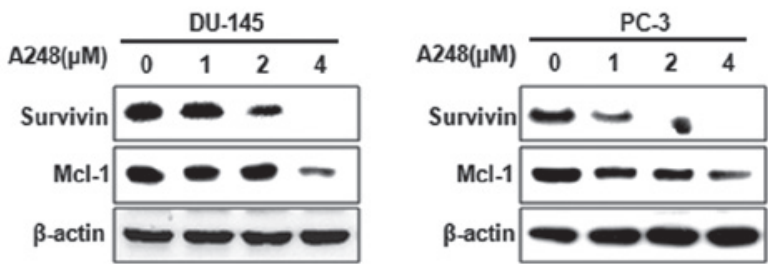

$\mathbf{B}$
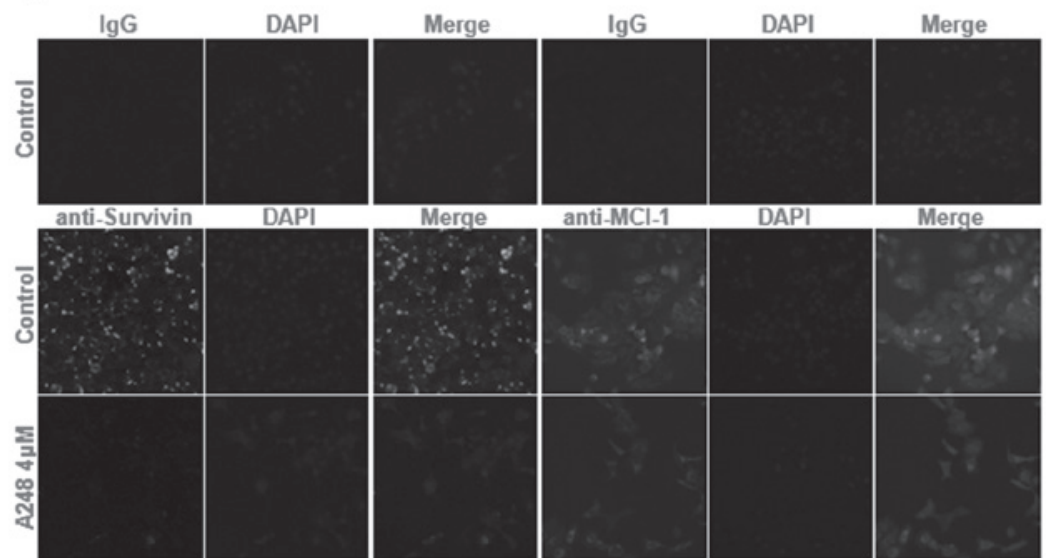

Figure 4. A248 inhibits survivin and Mcl-1 expression through Sp1 downregulation in DU145 and PC3 cells. (A) Cells were treated with the indicated concentrations of A248 for $72 \mathrm{~h}$, and survivin and Mcl-1 proteins were detected by western blot analysis. $\beta$-actin expression was used as an internal loading control. (B) DU145 cells were treated with $4 \mu \mathrm{M}$ of A248 for $72 \mathrm{~h}$ and immunostained with IgG or survivin and Mcl-1 antibodies. DAPI, 4'-6-diamidino2-phenylindole; Sp1, specificity protein 1.

to significantly decrease Sp1 protein in a concentration- and time-dependent manner as determined by western blot analysis (Fig. 3A and B). The expression level of Sp1 protein in DU145 cells was also determined using immunocytochemical analysis. The results showed that $\mathrm{Sp} 1$ immunostaining was observed in DU145 cells treated with DMSO (vehicle control); however, A248 significantly decreased Sp1 staining (Fig. 3C).
A248 inhibits survivin and Mcl-1 expression through Spl downregulation in DU145 and PC3 cells. We have previously demonstrated that the downregulation of Sp1 inhibits cell proliferation, induces apoptosis and affects the expression of survivin and Mcl-1 proteins (7). Thus, we next investigated whether survivin and Mcl-1 are involved in A248-induced apoptosis in DU145 and PC3 cells. The results showed that survivin and Mcl-1 protein expression was significantly 
decreased in DU145 and PC3 cells treated with A248 (Fig. 4A). Immunocytochemical analysis clearly confirmed that survivin and Mcl-1 were markedly decreased in DU145 cells treated with A248 (Fig. 4B).

\section{Discussion}

HDAC inhibitors have been focused on in numerous studies on anticancer agents $(9,12,13)$; from a clinical perspective, there are a large number of completed or ongoing clinical trials on these agents $(14,15)$. Despite the increasing interest in HDAC inhibitor therapies, the fundamental mechanisms via which these agents exert their anticancer effects remain unclear. An improved understanding of the association between various target genes and types of cancer have led several researchers to consider HDAC inhibitors as potent agents that may be able to interfere with cancer cell proliferation and/or survival. Recently, numerous studies have shown that HDAC inhibitors significantly reduce prostate cancer cell growth $(11,16-18)$. In the present study, we assessed the inhibitory effect of A248, a novel synthetic HDAC inhibitor, in prostate cancer lines. A248 was shown to strongly inhibit DU145 and PC3 prostate cancer cell viability. It has also been reported that various HDAC inhibitors arrest cell cycle progression and induce apoptosis in prostate cancer cells $(11,17,19-22)$. Thus, we next investigated the effect of A248 on apoptosis in prostate cancer cell lines using DAPI staining and via determination of the cell population in the sub-G1 phase of the cell cycle. We found that A248 caused an accumulation of cells in the sub-G1 phase of the cell cycle; nuclei condensation and fragmentation of DU145 and PC 3 cells by A248 was observed, suggesting that A248 is important in apoptotic signaling, including cell-cycle arrest in the sub-G1 phase, nuclei condensation and fragmentation. Therefore, A248 is suggested to be associated with apoptotic cell death.

Notably, although Sp1 is an essential transcription factor for a number of genes, it is overexpressed in numerous human cancer cells (23-29). Several studies have demonstrated that $\mathrm{Sp} 1$ is important in the pathogenesis of human cancer and that it constitutes a promising therapeutic target $(2,5,8,24,30-34)$. Our previous studies also found that $\mathrm{Sp1}$ is overexpressed in prostate cancer cells compared with normal cells $(7,8,35)$. Yu et al (36) reported that butyrate, a HDAC inhibitor, induces the downregulation of Sp1 in colon cancer cells, suggesting that $\mathrm{Sp} 1$ protein may be modulated by this HDAC inhibitor (36). Thus, we examined the effects of A248 on the expression of Sp1 protein in DU145 and PC3 prostate cancer cells. A248 was shown to significantly decrease the expression of Sp1 protein in a concentration- and time-dependent manner. We also demonstrated that the overexpression of Sp1 protein in DU145 cells was clearly inhibited by A248, indicating that A248 targets Sp1 to induce apoptosis in prostate cancer cells. Sp1 is a mammalian transcription factor $(27,37)$ that binds to GC-rich sequences to regulate gene expression (38) and directly binds to the survivin and Mcl-1 promoters (39-42). Our previous studies have demonstrated that Sp1 is closely associated with the upregulation of survivin and Mcl-1 proteins, which are known to be important in cancer cell survival $(7,8,35)$. In the present study, our results showed that the treatment of DU145 and PC3 cells with A248 resulted in a decrease in the protein levels of survivin and Mcl-1. Using immunocytochemical analysis, survivin and Mcl-1 proteins were confirmed to be significantly inhibited by A248 in DU145 cells, indicating that A248 inhibits Mcl-1 and survivin through the downregulation of Sp1 to induce apoptotic cell death in prostate cancer.

In conclusion, to the best of our knowledge, we showed for the first time that A248 inhibits the growth of prostate cancer cells and that the growth inhibitory effects of A248 may be mediated by apoptosis. We also demonstrated that A248 treatment resulted in the downregulation of Sp1, which affected the expression levels of survivin and Mcl-1 proteins. Therefore, our findings suggest that A248 targeting Sp1 protein may be a potential therapeutic agent for prostate cancer.

\section{Acknowledgements}

This study was supported by the Basic Science Research Program through the National Research Foundation of Korea (NRF) funded by the Ministry of Education, Science and Technology (nos. 2012002481 and 2012003731).

\section{References}

1. Alshatwi AA, Hasan TN, Shafi G, Syed NA, Al-Assaf AH, Alamri MS and Al-Khalifa AS: Validation of the antiproliferative effects of organic extracts from the green husk of Juglans regia L. on PC3 human prostate cancer cells by assessment of apoptosisrelated genes. Evid Based Complement Alternat Med 2012: Feb 6, 2012 (Epub ahead of print).

2. Malek A, Núñez LE, Magistri M, et al: Modulation of the activity of $\mathrm{Sp}$ transcription factors by mithramycin analogues as a new strategy for treatment of metastatic prostate cancer. PLoS One 7: e35130, 2012.

3. Soriano-Hernández AD, Galvan-Salazar HR, MontesGalindo DA, et al: Antitumor effect of meclofenamic acid on human androgen-independent prostate cancer: a preclinical evaluation. Int Urol Nephrol 44: 471-477, 2012.

4. Sankpal UT, Abdelrahim M, Connelly SF, et al: Small molecule tolfenamic acid inhibits PC3 cell proliferation and invasion in vitro, and tumor growth in orthotopic mouse model for prostate cancer. Prostate 72: 1648-1658, 2012.

5. Lou Z, O'Reilly S, Liang H, Maher VM, Sleight SD and McCormick JJ: Down-regulation of overexpressed sp1 protein in human fibrosarcoma cell lines inhibits tumor formation. Cancer Res 65: 1007-1017, 2005.

6. Chintharlapalli S, Papineni S, Ramaiah SK and Safe S: Betulinic acid inhibits prostate cancer growth through inhibition of specificity protein transcription factors. Cancer Res 67: 2816-2823, 2007.

7. Choi ES, Shim JH, Jung JY, et al: Apoptotic effect of tolfenamic acid in androgen receptor-independent prostate cancer cell and xenograft tumor through specificity protein 1. Cancer Sci 102: 742-748, 2011.

8. Shim JH, Shin JA, Jung JY, et al: Chemopreventive effect of tolfenamic acid on $\mathrm{KB}$ human cervical cancer cells and tumor xenograft by downregulating specificity protein 1 . Eur J Cancer Prev 20: 102-111, 2011.

9. Zhang CZ, Pan Y, Cao Y, Lai PB, Liu L, Chen GG and Yun J: Histone deacetylase inhibitors facilitate dihydroartemisinin-induced apoptosis in liver cancer in vitro and in vivo. PLoS One 7: e39870, 2012.

10. Roh MS, Kim CW, Park BS, et al: Mechanism of histone deacetylase inhibitor Trichostatin A induced apoptosis in human osteosarcoma cells. Apoptosis 9: 583-589, 2004.

11. Vallo S, Mani J, Stastny M, et al: The prostate cancer blocking potential of the histone deacetylase inhibitor LBH589 is not enhanced by the multi receptor tyrosine kinase inhibitor TKI258. Invest New Drugs 31: 265-272, 2013.

12. Rikiishi H: Autophagic and apoptotic effects of HDAC inhibitors on cancer cells. J Biomed Biotechnol 2011: May 18, 2011 (Epub ahead of print).

13. Perego P, Zuco V, Gatti L and Zunino F: Sensitization of tumor cells by targeting histone deacetylases. Biochem Pharmacol 83: 987-994, 2012. 
14. Khan $\mathrm{O}$ and La Thangue NB: HDAC inhibitors in cancer biology: emerging mechanisms and clinical applications. Immunol Cell Biol 90: 85-94, 2012.

15. Marks PA: The clinical development of histone deacetylase inhibitors as targeted anticancer drugs. Expert Opin Investig Drugs 19: 1049-1066, 2010.

16. Chou YW, Chaturvedi NK, Ouyang S, et al: Histone deacetylase inhibitor valproic acid suppresses the growth and increases the androgen responsiveness of prostate cancer cells. Cancer Lett 311: 177-186, 2011.

17. Hudak L, Tezeeh P, Wedel S, et al: Low dosed interferon alpha augments the anti-tumor potential of histone deacetylase inhibition on prostate cancer cell growth and invasion. Prostate 72 $1719-1735,2012$

18. Kim NH, Kim SN and Kim YK: Involvement of HDAC1 in E-cadherin expression in prostate cancer cells; its implication for cell motility and invasion. Biochem Biophys Res Commun 404: 915-921, 2011.

19. Gravina GL, Marampon F, Giusti I, et al: Differential effects of PXD101 (belinostat) on androgen-dependent and androgen-independent prostate cancer models. Int J Oncol 40: 711-720, 2012.

20. Zhou X, Yang XY and Popescu NC: Preclinical evaluation of combined antineoplastic effect of DLC1 tumor suppressor protein and suberoylanilide hydroxamic acid on prostate cancer cells. Biochem Biophys Res Commun 420: 325-330, 2012.

21. Lai MT, Yang CC, Lin TY, Tsai FJ and Chen WC: Depsipeptide (FK228) inhibits growth of human prostate cancer cells. Urol Oncol 26: 182-189, 2008.

22. Bjorkman M, Iljin K, Halonen P, Sara H, Kaivanto E, Nees M and Kallioniemi OP: Defining the molecular action of HDAC inhibitors and synergism with androgen deprivation in ERG-positive prostate cancer. Int J Cancer 123: 2774-2781, 2008.

23. Abdelrahim M, Smith R 3rd, Burghardt R and Safe S: Role of Sp proteins in regulation of vascular endothelial growth factor expression and proliferation of pancreatic cancer cells. Cancer Res 64: 6740-6749, 2004

24. Abdelrahim M, Samudio I, Smith R 3rd, Burghardt R and Safe S Small inhibitory RNA duplexes for Sp1 mRNA block basal and estrogen-induced gene expression and cell cycle progression in MCF-7 breast cancer cells. J Biol Chem 277: 28815-28822, 2002.

25. Safe $\mathrm{S}$ and Abdelrahim M: Sp transcription factor family and its role in cancer. Eur J Cancer 41: 2438-2448, 2005.

26. Yao JC, Wang L, Wei D, et al: Association between expression of transcription factor Sp1 and increased vascular endothelial growth factor expression, advanced stage, and poor survival in patients with resected gastric cancer. Clin Cancer Res 10 : 4109-4117, 2004

27. Wang L, Wei D, Huang S, et al: Transcription factor Sp1 expression is a significant predictor of survival in human gastric cancer. Clin Cancer Res 9: 6371-6380, 2003.

28. Zannetti A, Del Vecchio S, Carriero MV, et al: Coordinate up-regulation of Sp1 DNA-binding activity and urokinase receptor expression in breast carcinoma. Cancer Res 60: 1546-1551, 2000.
29. Hosoi Y, Watanabe T, Nakagawa K, et al: Up-regulation of DNA-dependent protein kinase activity and Sp1 in colorectal cancer. Int J Oncol 25: 461-468, 2004

30. Ishibashi $\mathrm{H}$, Nakagawa $\mathrm{K}$, Onimaru $\mathrm{M}$, et al: $\mathrm{Sp} 1$ decoy transfected to carcinoma cells suppresses the expression of vascular endothelial growth factor, transforming growth factor beta1, and tissue factor and also cell growth and invasion activities. Cancer Res 60: 6531-6536, 2000

31. Chadalapaka G, Jutooru I, Chintharlapalli S, Papineni S, Smith R 3rd, Li X and Safe S: Curcumin decreases specificity protein expression in bladder cancer cells. Cancer Res 68: 5345-5354, 2008

32. Jutooru I, Chadalapaka G, Lei P and Safe S: Inhibition of NFkappaB and pancreatic cancer cell and tumor growth by curcumin is dependent on specificity protein down-regulation. J Biol Chem 285: 25332-25344, 2010.

33. Chu S and Ferro TJ: Sp1: regulation of gene expression by phosphorylation. Gene 348: 1-11, 2005.

34. Deniaud E, Baguet J, Chalard R, et al: Overexpression of transcription factor $\mathrm{Spl}$ leads to gene expression perturbations and cell cycle inhibition. PLoS One 4: e7035, 2009.

35. Choi KH, Shim JH, Huong LD, Cho NP and Cho SD: Inhibition of myeloid cell leukemia-1 by tolfenamic acid induces apoptosis in mucoepidermoid carcinoma. Oral Dis 17: 469-475, 2011.

36. Yu DC, Waby JS, Chirakkal H, Staton CA and Corfe BM: Butyrate suppresses expression of neuropilin I in colorectal cell lines through inhibition of Sp1 transactivation. Mol Cancer 9: 276, 2010.

37. Xu J, Zhou JY, Wei WZ, Philipsen S and Wu GS: Sp1-mediated TRAIL induction in chemosensitization. Cancer Res 68: 6718-6726, 2008.

38. Kadonaga JT, Courey AJ, Ladika J and Tjian R: Distinct regions of Sp1 modulate DNA binding and transcriptional activation. Science 242: 1566-1570, 1988.

39. Pietrzak M and Puzianowska-Kuznicka M: p53-dependent repression of the human MCL-1 gene encoding an anti-apoptotic member of the BCL-2 family: the role of Sp1 and of basic transcription factor binding sites in the MCL-1 promoter. Biol Chem 389: 383-393, 2008.

40. Li F and Altieri DC: Transcriptional analysis of human survivin gene expression. Biochem J 344: 305-311, 1999.

41. Li Y, Xie M, Yang J, Yang D, Deng R, Wan Y and Yan B: The expression of antiapoptotic protein survivin is transcriptionally upregulated by DEC1 primarily through multiple spl binding sites in the proximal promoter. Oncogene 25: 3296-3306, 2006.

42. Wu J, Ling X, Pan D, et al: Molecular mechanism of inhibition of survivin transcription by the GC-rich sequence-selective DNA binding antitumor agent, hedamycin: evidence of survivin down-regulation associated with drug sensitivity. J Biol Chem 280: 9745-9751, 2005. 